\title{
The Problems and Countermeasures of Supply Chain Logistics Information System Integration in Auto Parts Enterprises
}

\author{
Ming Li \\ School of Management \\ Guangxi University of Science and Technology \\ LiuZhou, GuangXi P.R.China, 545006 \\ E_mail: wuqingmingjian@qq.com \\ Changchun Jiang \\ .Wuhan ZhiMing Information Co.,Ltd, \\ Wuhan,Hubeii P.R.China, 43007 \\ E_mail: jiangchangchun@zmit.com
}

\author{
Yuandi Zhou* \\ 2011 levels of information management and information \\ system, School of Management \\ Guangxi University of Science and Technology \\ LiuZhou, GuangXi P.R.China, 545006 \\ E_mail: zhouyuandi11@163.com
}

\begin{abstract}
Changes in the automotive industry production management model has led to the new generation of supply chain management, and enterprise management group in the industry business association, IT strategy had a significant impact, this paper analyzes the application and integration of information systems for the automotive industry status quo find restrict the operation of the main problems enterprise collaboration, consisting of a series of strategies on the basis of multi-enterprise information system integration measures, so that some of the advanced management ideas and technology can get IT application and development in the automotive industry, so that enterprises have more strong resilience and competitiveness, to effect the operation of supply chain collaboration.
\end{abstract}

Keywords- Supply Chain Management; Information System Integration; Collaboration; Order-To-Delivery.

\section{INTRODUCTION}

Automotive industry production management transition from mass production to production orders and even water mass customization phase, while the automotive industry has its own proprietary technology, complex business processes, extensive distribution channels and generate vast amounts of information every day, all these to the enterprise information management and information coordination bring new challenges. Produce a new supply chain management mode must request the informatization construction of automotive industry category is no longer limited to the internal system of single enterprise, the value chain within the enterprise to do the best, but extend to establish common conducive to the whole industry system of the whole supply chain information flow with different industry background associated business partners. In this paper, through analyzing the present situation of automotive industry supply chain management in China is analyzed, we find the influence and restriction of information system application and integration problems, on this basis, the analysis of the automobile manufacturing industry, the core business research and based on the analysis, then the multi enterprise information system integration research, proposed the information system with the characteristic of automotive industry integration countermeasures, in order to seek the truth should shun line cooperation, win-win implementation of the automotive industry, improve the core competitiveness and the fight against the whole industry play potential[1].

\section{AUTOMOTIVE INDUSTRY SUPPLY CHAIN MANAGEMENT STATUS}

In view of the core status in the supply chain in the automotive industry, the development trend of auto industry is bound to the existing supply chain management model also bring far-reaching influence, in the face of new changes of market environment, based on the traditional business areas, the automotive industry supply chain has entered a new round of business transformation, mainly displays in the planning and control, purchasing, manufacturing, distribution services, etc.

\section{A. The Method of Plan and Control Field}

According to the market and the needs of users, in order to achieve flexible mixed flow production, according to the order in the field of program USES a variety of supply chain management mode with the combination of methods, such as production in inventory, order production or order for positioning mode, so as to realize the combination of multiple brands and product lines. Through the collaborative application at the source of supply chain planning field, can be control the whole industry chain in hand.

\section{B. What Can We Learn from Procurement Field}

According to the principle of value chain, OEMs to focus on their core business and core ability and the implementation of outsourcing strategy, thus we should not only for OEMs require suppliers provide fast and flexible response, and to be able to continue to reduce the cost. So, we need to make improvements in processes and technology suppliers, ensure its 
downstream supply chain the timeliness, validity and accuracy of the information transmission.

\section{Changes of Production and Manufacturing Field Will Take Place}

Dynamic external environment requires the production link can play some advantages of scale, but also can satisfy customers personalized, the characteristics of the demand, with the help of Toyota Corporation of lean production model, in the field of production will be present to stock production push pull type steering according to production order. The modern way of life began to human production mode t The Manufacturing sector ransformation, this transformation is very important for the automotive industry.

\section{The Problem of Circulation and Service Areas}

In the order management, business processing system the user order situation and background of e-commerce system is obtained in the integration, to meet user delivery date or time query demand; in logistics management, the introduction of professional third party logistics enterprises to meet the parts or the whole vehicle logistics services; in the network design, the use of heuristic the algorithm to optimize the allocation of resources, so that to achieve the best cost / benefit.

For the automotive industry manufacturers, the globalization of economy, enterprises continue cooperation, unity and the rationalization of product and brand management and so on several factors driving the car enterprises in the supply chain management changes, so in the field of supply chain management, will produce a series of new management ideas, methods and tools, such as order the mixed line production sequencing plan mode, auto product lifecycle management, B2B and B2C information integration model and the workshop oriented manufacturing execution information system.

\section{AUTO INDUSTRY INFORMATION SYSTEMS APPLICATION INTEGRATION PROBLEMS}

Facing the change of field of automobile supply chain management these fundamental and application of all kinds of information system plays an important role in the business management of automotive industry, automotive industry informatization construction has achieved initial results, in research and development, production, technology, management and sales and services in areas such as through the implementation of some domestic and foreign management software provider. Some of the professional management software, or through independent development and cooperative development established in line with its own characteristics of the enterprise and all kinds of information system to improve the efficiency of information resource development, access to information economy benefit. But between different departments of information technology and enterprise management development and fusion of range is limited to within the enterprise, no truly effective integration between enterprise internal various systems of course, between the enterprise information system on the synergy also remain in the theoretical research stage, to be truly collaborative still need to do a lot of basic work, a series of unique problems and the current automobile manufacturing industry in the procurement, manufacturing, sales and service stages exist is troubled by the enterprise to realize the collaborative obstacles in the supply chain, mainly in the:

\section{A. A Large Number of Redundant System Makes the Business Association Group of Enterprises Cannot Realize the Collaborative Commerce Close}

The automotive industry information system applications including initial customization and dealer orders, the enterprise production scheduling, parts companies supply of spare parts, logistics company cohesion transportation to final 4S shop marketing, due to the automotive industry and the rise of the boom, many application systems of enterprises from the constantly by the acquiring enterprise[2]. Therefore, enterprises have to face information system or application is difficult to reuse the redundancy from the function. In many enterprises, the various business units are independent of each other, thereby causing a great obstacle for some function and system of enterprise reuse. The redundant system for enterprises to increase costs in the deployment of new products and services, but also delayed the time, because a small change will be a system resulted in almost every system or application changes. Cannot reuse will eventually consume the limited resources more, need to develop and deploy time longer in the delivery of new application. So in the automotive industry in the internal information system integration and integration, will encounter thorny issues, such as the flexible and efficient system integration, data sharing, and different exchange platform. Because the software system is not uniform, different departments within the company are not up to the information resources sharing, and fragmented into a personal information "isolated island", so that the working efficiency is greatly reduced. Moreover, due to the implementation of the different information standards and norms, between enterprises in the auto industry information exchange and sharing more barriers and heavy.

\section{B. Fast Dynamic Change of Market Demand of Business Process Change Frequently}

From a business process perspective, the automotive industry production mode from mass production to mass customization production orders even transition stage, in order to improve business flexibility, quick to grasp the market beating, meet consumer characteristics, diversified and personalized demand, improve customer response and improve operational efficiency, enterprise business processes must also be changed with the need to in order to achieve the above goals, such as to achieve customized, satisfy the customer in the configuration, color, delivery time requirements, the need for material purchasing, planning and control, sales and other business process redesign.

\section{Business Process Changes Will Affect the Enterprise IT Strategy Planning}

From the perspective of IT, enterprises need to keep up with the fierce competition in the pace of the market demand for new business functions, about $80 \%$ of the enterprise's IT budget is spent on maintenance and enhance existing applications, and create these existing applications and not fully considering the flexibility problems, therefore, although the 
business transformation and the use of new and enhanced process, IT department but have no ability to must change. Traditional applications and architectures are unable to keep up with the pace of business innovation, and this is mainly because the process cannot be on demand to adapt to the needs of the business [3]. Business requirements are usually converted to isolated IT projects, these projects cannot be collaboration between members; created for different IT projects reusability is usually very low. Create a response to the unknown flexible enough application is required for the application of system development method. But, is usually very difficult to determine to create a flexible IT application further budget requirements. Because the traditional application architecture inflexibility, even a small improvement also need to spend a great cost, so it is almost impossible to adjust.

\section{Closed System Architecture Can't Meet the Needs of Your Community on Supply Chain Management}

In cost, quality, price, delivery time, under the constraint of industry homogeneity competition between enterprises is also very fierce, subject to a group of associated with companies out of business in your community, and the new enterprise if have competitive power can enter the your community, the based on traditional integration methods, such as special interface, middleware or gateway form the enterprise information system integration model of challenges, for example, there are $n$ application must connect directly and interface, Point to point mode requires the establishment of $n(n-1)$ connection. As a result, if you need to connect a new application, so we must build, test, and document $2 \mathrm{n}$ connection. It will bring huge problem to the maintenance of these applications, because must modify each existing applications that they contain new interface, the corresponding test cost will rise exponentially. 's final assembly plant in this case, in the core position to consider an open integrated architecture, such as which has the function of self-organizing, adaptive software autonomy mechanism, on the basis of synergy to fast, improve efficiency.

\section{APPLICATION INTEGRATION STRATEGIES AUTOMOTIVE INDUSTRY INFORMATION SYSTEM}

In order to solve the problems between the enterprise supply chain management in the automotive industry business collaboration loose, poor information exchange or delay in product customization, raw material supply, material control, production planning and control, sales and service and rapid response to a series of questions, the delivery to order through the (Order-To-Delivery, OTD) study the mode of production, according to one or more of the business process of supply chain management, automotive industry product customization and service collaboration enterprise main business, by business process modeling based on business collaboration model, the establishment of business related enterprises group and put forward a comprehensive solution for business collaboration. The suggestions include design, key technology to business process as the main line of manufacturing and management integration and enterprise and enterprise integrated method between heterogeneous systems, open integration of digital enterprise system integration service oriented framework, the development of inter enterprise collaborative information system integration platform and a series of strategy, collaborative operation by combining the application of these strategies to support the automotive industry enterprise group, to realize the enterprise business close cooperation, information timely, accurate, efficient, safe exchange.

\section{A. Supply Chain Business Collaboration Model of Business Process Modeling Value Flow is Established Based on OTD in Automotive Industry}

Analysis of problems existing in the management of the supply chain of automotive industry in the rapid dynamic changes in the market demand, combined with China's automotive industry in the current application situation of OTD production mode based on the reference of other enterprises, both at home and abroad the latest progress, according to the idea of collaborative management, guided by the business driven, the optimization of enterprise group based on business process flow value, establish business process center, put forward the enterprise group of new supply chain management mode, with the thought of system engineering, the first after the decomposition of comprehensive, from the collaborative procurement, collaborative manufacturing, sales, service and Cooperation Cooperative collaborative management angle respectively to study their causes, situation, finally establish business association enterprise group business collaboration model. And through the business process management to maintain the system integration platform of business processes or enterprise group after the change, business process monitoring center, capability of major events, so that enterprises can improve their business facing the changes and problems.

\section{B. The Establishment of the Open Service Oriented Software Architecture}

According to the requirements of service oriented modeling (SOA) will be treated as each business processes into reusable components, transplant, based on the separation of concerns and loose coupling architecture principles derived from best practices, such as inheritance, EAI, message bus, process integration, data integration and so on outstanding technology, design a kind of software architecture, it can be released through public or can be found in the interface to provide services to other applications, these services can be invoked by other applications through the network. To system integration for the purpose to develop business driven enterprise information system integration components, integration components are independent of the business system and implementation in each of the messaging between business systems, data extraction and release, and other functions. And security platform to be integrated by the independence between each system, realize the application integration in the form of loose coupling [4]. From the development of the integration components, provide understanding of the visibility of the business process as well as access to the entire enterprise information consistent way inside. This way is very flexible and powerful, and can reduce the development cost and cost of ownership, and reduce the risk of system implementation.

\section{Establish a Third-party Enterprise Data Centers with Self-organizing, Adaptive Capacity}

Based on self-organization of third-party enterprise data center, adaptive, software autonomy mechanism analysis and 
research, the system integration platform was established based on intelligent agent technology, to meet your community in the information communication between timely, open and security requirements. Established over business-driven enterprise information system of data center, using data center provides data integration based on enterprise application integration using XML message said, based on the publish/subscribe mechanism of information sharing and message routing allows business system of information sharing is simple and easy to change, the intelligent agent technology, can connect heterogeneous systems and operation environment, research for collaborative software service under the network environment, has the characteristics of autonomous software system structure and key technology together, forming a service-oriented autonomous system integration platform, make form a loose coupling between business systems, can not only increase the new service component and remove the old service components, and can guarantee the local error system can better recovery, to ensure that the data exchange platform has higher robustness and expansibility.

\section{Follow the Implementation of the Scientific Principles}

In a core position in the supply chain assembly plant as the basis, to the upstream and downstream business associated enterprises double divergence, eventually form the coverage for the whole of your community. Your community in each enterprise close cooperation, in accordance with the "overall planning, step-by-step implementation, the key breakthrough, benefit driven" principle, the implementation of the strategy and concrete application scheme. First of all, based on automotive industry supply chain based on OTD production mode synergy model, then based on the business driven mainly to the enterprise business process modeling, the formation of a service-oriented architecture based on component, in particular, phased development and implementation step; Focused in the process of system development, closely combined with the enterprise actual demand, maximum limit is compatible with the existing work mode, enterprise is the most urgent needs to solve problems; Based on complete lines of business division in the process of system implementation in the implementation stage, according to the business problem urgent and important degree sorting, easy to difficult, after first from the inside out, institution transference for the implementation of the system.

\section{CONCLUSION}

Through multiple enterprise information system integration mechanism, can guide the development of automotive industry in the new century management ideology, organization form, operation pattern. Embodies the management thought of decentralized management, humanistic management, flexible management, strategic management; Contains the competitive cooperation, the use of external resources supernormal development introduction of information technology in enterprise management mechanism, auto industry, the introduction of enterprise information technology synergy mechanism in market transactions and other advanced management thought[5]. The auto industry can take the information technology as the core cluster resources, take the form of strategic alliance, the relevant enterprises by seeking with complementary resource advantage or peer business strength, realize the various alliance participants competition and coordination, risks and costs, the joint development of new products, develop new markets, so that within the alliance resource sharing, maximum degree to achieve a win-win situation, after the integration and optimization of operation of enterprise internal and external information system, the information age of the automotive industry in various business association partners will be an integrated digital enterprise, based on the enterprise management concept, management method, the advanced information technology, continuous improvement and continuous innovation, so that the enterprises have stronger strain capacity and competitive ability, to achieve synergy and competition effect obviously.

\section{ACKNOWLEDGMENT}

This research was financially supported by Guangxi autonomous region level and the National college students' innovation and entrepreneurship training plan project: "Research on supply chain logistics information integration and innovation of intelligent multi-agent system based on auto parts enterprises" (Guangxi autonomous region level project number: 201410594088), (National project number: 201410594036).

\section{REFERENCES}

[1] Peng Junsong, "the automotive industry supply chain strategy, management and information system", Beijing, electronic machinery industry press, pp. 29-51, Apri 2006.

[2] Ma Shihua, Lin Yong, Chen Zhixiang, "supply chain management", Beijing, mechanical industry press,pp.12-90, may 2000.

[3] Sun Hongguang, "towards the information age of Chinese auto industry management information technology application",industrial engineering and managemen, 4th ed, pp. 23-56, 2003

[4] Liu Yunhua, Chen Liping, Zhong Yifang, "mass production ready integrated information management system and key technology research", computer engineering and applications, 3rd ed, pp.124-158, 2003.

[5] Wang Lin, "research cooperative information system of modern enterprise", Wuhan University of Technology master's thesis ,pp.13-167, Dec 2002. 